\title{
On the performance of West's bubble test: A simulation approach
}

\author{
Aydin Yuksel $^{\mathrm{a}}$, Levent Akdeniz ${ }^{\mathrm{b}, *}$, Aslihan Altay-Salih ${ }^{\mathrm{b}}$

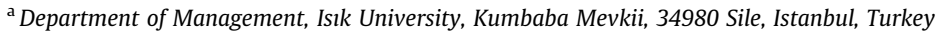 \\ ${ }^{\mathrm{b}}$ Faculty of Business Administration, Bilkent University, 06800 Bilkent, Ankara, Turkey
}

\section{A R T I C L E I N F O}

Keywords:

Speculative bubble test

Present value model

Asset pricing

\begin{abstract}
A B S T R A C T
In this research we examine the ability of West's bubble test [1] in detecting speculative bubbles using Brock's (1982) [2] intertemporal general equilibrium model of asset pricing as the basis for a simulation study. In this setting, (1) the economy, by construction is efficient and produces the maximally possible amount of welfare for society, and (2) asset prices reflect the utility-maximizing behavior of consumers and the profit-maximizing behavior of firms. We find that the West's bubble test flag as "bubbles" in the simulated data yet the data is produced from an economy in which markets are efficient in welfare production.
\end{abstract}

(c) 2010 Elsevier Inc. All rights reserved.

\section{Introduction}

The steep rises and following sudden declines in the real equity prices in the United States during the last three decades have attracted a lot of attention in the academia. Some researchers suggested that asset prices contain bubbles in addition to their fundamental values. Theoretically, the equilibrium price of an asset is simply the present value of its expected future cash flows. If market prices are driven by fundamentals, then fluctuations in equity prices should only reflect changes in their expected future dividends. Are such movements in real equity prices during the last three decades really a reflection of changing market fundamentals or is it a result of self-fulfilling expectations that investors are willing to pay more for a stock today than its intrinsic value because they expect to be able to sell it even more in the future.

A vast literature has emerged to study whether or not the observed volatility in equity prices is justified by fluctuations in expected dividends. Shiller [3] argued that the ex-post rational prices should be at least as variable as the observed prices because observed prices are based on expected dividends and do not have the variation introduced by future forecast errors. However, Shiller [3] documents that observed prices are more volatile than the ex-post rational price series. ${ }^{1}$ Although Shiller [3] used his findings to argue about the validity of the present value model, other authors like Tirole [4], Blanchard and Watson [5] related Shiller's [3] findings to the existence of rational bubbles.

Prior research has hypothesized and examined bubbles that differ in nature. These can be classified, in general, as either exogenous or intrinsic bubbles based on if they are exogenous to or depend in a non-linear deterministic way on fundamentals. Exogenous bubbles are examined among others by Flood and Garber [7], Blanchard and Watson [5], and Flood and Garber [8], while papers analyzing intrinsic bubbles include Froot and Obstfeld [9] and Driffill and Sola [10].

Several tests have been proposed in the literature for the presence of bubbles. ${ }^{2}$ Some of these require a specific parameterization of the bubble process; some investigate the stationary properties of price and dividend data and use unit root tests, autocorrelation patterns and cointegration tests. One of the tests that neither requires a specific parameterization of the bubble

\footnotetext{
* Corresponding author.

E-mail addresses: yuksel@isikun.edu.tr (A. Yuksel), akdeniz@bilkent.edu.tr (L. Akdeniz), asalih@bilkent.edu.tr (A. Altay-Salih).

1 See Akdeniz et al. [6] for a review.

2 See Gurkaynak [14] for a detailed survey of econometric tests of asset price bubbles.
} 
process nor uses integration/cointegration based analysis is West [1]. Due to its design, this test can - in principle - detect any bubble that is correlated with dividends. This is a desirable feature since overreaction to dividend news is argued to be an important factor contributing to the formation of a rational bubble [11]. The test procedure involves sequentially testing the model specification and the no-bubbles hypothesis. In testing the latter, a set of parameters are calculated by two alternative methods. Under the assumption of no bubbles, the parameter estimates obtained from these two methods should be equal apart from sampling error, while in the presence of rational bubbles, the estimates should differ. ${ }^{3}$

Although West's test is considered to be a milestone test in detecting bubbles in data, it has been criticized in the literature in many ways. ${ }^{4}$ One such criticism involves the approximation used in calculating the test statistic. West's test is similar to Hausman's [12] test in that both are based on the comparison of two sets of estimates of the same coefficients. However, as noted by Dezhbakhsh and Demirguc-Kunt [13], they differ in a major way. In Hausman, the coefficients of the equation of interest are estimated directly by using two different estimators. In West, there is indirect estimation which involves the expression of the coefficients of interest, namely the distributed lag coefficients, in terms of coefficients from Euler and dividend ARIMA equations. Since the relationship is non-linear, the covariances of the distributed lag coefficients can only be approximated from the covariances of coefficients from Euler and dividend ARIMA equations. Dezhbakhsh and Demirguc-Kunt [13] argue that this approximation could exaggerate the chi-square statistic used by West, resulting in a rejection of the "no-bubble" hypothesis when there are no bubbles. ${ }^{5}$

In the 1990s, some researchers have shifted their methodologies away from the above econometric analysis toward models of human psychology. Thus, a new research area namely behavioral finance has emerged. Behavioral finance has become a complement to the econometric analysis and many researchers have spent a lot of time and energy to explain anomalies in prices by using behavioral models. ${ }^{6}$ However, the econometric analysis of stock prices and their correspondence to efficient markets theory is still an interest of the recent research.

Abreu and Brunnermeier [23] show that asset bubbles can persist despite the presence of rational arbitrageurs. They argue that the resilience of bubbles can be attributed to the inability of the arbitrageurs to synchronize their selling strategies. Heston et al. [24] present evidence for existence of bubbles from multiple solutions of the Black-Scholes-Merton model and possibly infeasible arbitrageurs. Pastor and Veronesi [25] calibrated the stock valuation model by introducing uncertainty in average future profitability and showed that the observed high volatility is not a sign of a bubble. Ghezzi and Piccardi [26] propose a dividend valuation model by using Markov chain and show their model is in accordance with the empirical data. Nwogugu [27] criticizes the econometric models of asset pricing since they do not account for many facets of psychological behavior and decision making processes of agents. Cunado et al. [28] argue that the conclusions of the existence of bubbles in econometric tests might be due to the sampling frequency of data. In a survey paper, Gurkaynak [14] suggests that the econometric detection of asset price bubbles cannot be achieved with a satisfactory degree of certainty, and concludes that the literature is still unable to distinguish bubbles from time varying and regime shifting fundamentals.

In this study, we follow the argument of Dezhbakhsh and Demirguc-Kunt [13] and design an experiment to examine the ability of the West's test to detect bubbles. We simulated Brock's [2] general equilibrium model of asset pricing to obtain equity price and dividend series to be used in place of actual data. The simulated data are derived from a theoretical economic model, thus it does not contain any bubbles. More specifically, in our setting, (1) the economy, by construction is efficient and produces the maximally possible amount of welfare for society, and (2) asset prices reflect the utility-maximizing behavior of consumers and the profit-maximizing behavior of firms. Therefore the West's test should not reject the no-bubble hypothesis in this set up.

Brock's [2] general equilibrium model of asset pricing represents an extension of Lucas's [29] exchange economy theory to production-based asset pricing models. This extension opens up avenues to many applications, which are not possible in a pure exchange setting with no production activities. In Brock's dynamic asset pricing model, shocks directly affect the production processes and hence asset returns are linked to the underlying sources of production and uncertainty. By incorporating the shocks into the production processes, Brock's model has the sources of uncertainty in the asset prices directly tied to economic fluctuations in output levels. However, in the endowment models, the process on the endowment is exogenous and there is neither capital accumulation nor production. Thus, Brock's production-based asset pricing model includes many useful components that make the results more realistic. In addition, Brock's model has been successful to predict many empirical findings and shed light on empirical anomalies. ${ }^{7}$ Lucas type endowment models do not have sufficient flexibility to predict the extent of the empirical facts.

The rest of the paper is organized as follows: In Section 2 we introduce the model and the simulation of the data. Section 3 discusses the West test and its implementation and results of the tests and Section 4 concludes the paper.

\footnotetext{
${ }^{3}$ See Casella [15] and Meese [16] for the applications of West's test.

${ }^{4}$ See Dezhbakhsh and Demirguc-Kunt [13] and Flood et al. [17].

${ }^{5}$ Another issue, as West [1] discusses in Footnote 3, is that the test may not be consistent: "if there are bubbles, the asymptotic probability that the test will reject the null may not be unity, even though the two sets of parameter estimates will be different with probability one in an infinite sized sample." This could result in a failure to detect bubbles when bubbles are present.

${ }^{6}$ There is a lot of research in this area that is impossible to summarize here. The interested reader should refer to Thaler [18], Shefrin [19,20], Barberis and Thaler [21] and Vissing-Jorgensen [22].

7 See Akdeniz and Dechert [30,31], and Akdeniz [32].
} 


\section{Model}

\subsection{The growth model}

The model we use as the basis for our study is the standard growth model with production, as specified in Brock [33]. This is a model of economic growth with an infinitely lived representative consumer. In this section, we heavily borrow from Brock [33] and recapitulate the essential elements of the model:

$$
\begin{array}{ll}
\max _{c_{t}, x_{i t}} & E\left[\sum_{t=0}^{\infty} \beta^{t} u\left(c_{t}\right)\right] \\
\text { subject to : } & x_{t}=\sum_{i=1}^{N} x_{i t}, \\
& y_{t+1}=\sum f\left(x_{i t}, \xi\right), \\
& c_{t}+x_{t}=y_{t}, \\
& c_{t} x_{i t} \geqslant 0, \\
& y_{0} \text { historically given, }
\end{array}
$$

where $E$ is the mathematical expectation operator, $\beta$ is the discount factor on future utility, $u$ is the utility function of consumption, $c_{t}$ is consumption at date $t, x_{t}$ is capital stock at date $t, y_{t}$ is output at date $t, f_{i}$ is production function of process $i$ plus undepreciated capital, $x_{i t}$ is capital allocated to process $i$ at date $t, \delta_{i}$ is depreciation rate for capital installed in process $i$, and $\xi_{t}$ is the shock parameter. Note that

$$
f_{i}\left(x_{i t}, \xi_{t}\right)=g_{i}\left(x_{i t}, \xi_{t}\right)+\left(1-\delta_{i}\right) x_{i t},
$$

where $g_{i}\left(x_{i t}, \xi_{t}\right)$ is the production function of process $i$.

The optimizer's objective is to maximize the expected value of the discounted sum of utilities over all consumption paths and capital allocations. ${ }^{8}$ The working of the model, according to Brock [2] is.

There are $N$ different processes. At date $t$ it is decided how much to consume and how much to hold in the form of capital. It is assumed that capital goods can be costlessly transformed into consumption goods on a one-for-one basis. After it is decided how much to hold in the form of capital, then it is decided how to allocate capital across the $N$ processes. After the allocation is decided nature reveals the value of $r_{t}$, and $g_{i}\left(x_{i t}, r_{t}\right)$ units of new production are available from process $i$ at the end of period $t$. But $\delta_{i} x_{i t}$ units of capital have evaporated at the end of period $t$. Thus, the net new produce is $g_{i}(x-$ $\left.{ }_{i t}, r_{t}\right)-\delta_{i} x_{i t}$ from process $i$. The total produce available to be divided into consumption and capital stock at date $t+1$ is given by

$$
\sum_{i=1}^{N}\left[g_{i}\left(x_{i t}, r_{t}\right)-\delta_{i} x_{i t}\right]+x_{t}=\sum_{i=1}^{N}\left[g_{i}\left(x_{i t}, r_{t}\right)+\left(1-\delta_{i}\right) x_{i t}\right] \equiv \sum_{i=1}^{N} f_{i}\left(x_{i t}, r_{t}\right) \equiv y_{t+1},
$$

where

$$
f_{i}\left(x_{i t}, r_{t}\right) \equiv g_{i}\left(x_{i t}, r_{t}\right)+\left(1-\delta_{i}\right) x_{i t}
$$

denotes the total amount of produce emerging from process $i$ at the end of period $t$. The produce $y_{t+1}$ is divided into consumption and capital stock at the beginning of date $t+1$, and so on it goes.

Note that Brock's [2] notation for the shock parameter is " $r_{t}$ " whereas in this study shock parameter is denoted by " $\xi_{t}$ ". For a full interpretation of the model see Brock [2].

The main assumptions for this model are:

(A1) the functions $u$ and $f_{i}$ are concave, increasing, twice continuously differentiable, and satisfy the Inada conditions;

(A2) the stochastic process is independent and identically distributed;

(A3) the maximization problem has a unique optimal solution.

The first-order conditions for the intertemporal maximization are:

$$
\begin{aligned}
& u^{\prime}\left(c_{t-1}\right)=\beta E_{t-1}\left[u^{\prime}\left(c_{t}\right) f_{i}^{\prime}\left(x_{i t}, \xi_{t}\right)\right], \\
& \lim _{t \rightarrow \infty} \beta^{t} E_{t-1}\left[u^{\prime}\left(c_{t}\right) x_{i t}\right]=0 .
\end{aligned}
$$

Eq. (2.7) is the one that is used below to drive a numerical solution to the growth model. Since the problem given by Eqs. (2.1)-(2.6) is time stationary the optimal levels of $c_{t}, x_{t}, x_{i t}$ are functions of the output level $y_{t}$, and can be written as:

$$
c_{t}=g\left(y_{t}\right), \quad x_{t}=h\left(y_{t}\right), \quad x_{i t}=h_{i}\left(y_{t}\right) .
$$

\footnotetext{
${ }^{8}$ The $x^{\prime}$ s at date $t$ must be measurable with respect to the $x_{i}^{\prime}$ s through date $t-1$.
} 
The objective is to solve the growth model for the optimal investment functions, $h_{i}$, to analyze the underlying implications of the asset pricing model. The first two functions in Eq. (2.9) can be expressed in terms of these investment functions:

$$
\begin{aligned}
& h(y)=\sum_{i=1}^{N} h_{i}(y), \\
& c(y)=y-h(y) .
\end{aligned}
$$

\subsection{An asset pricing model}

The asset pricing model in Brock [2] is much like the Lucas [29] model. The main difference between these two models is that Brock's [2] model includes production, thus by incorporating shocks in with the production processes, it has the sources of uncertainty in the asset prices directly tied to economic fluctuations in output levels and hence in profits.

The model is similar to the growth model. There is one representative consumer whose preferences are given in Eq. (2.1). On the production side there are $N$ different firms. Firms rent capital from the consumer side at the rate $r_{i t}$ to maximize their profits:

$$
\pi_{i, t+1}=f_{i}\left(x_{i t}, \xi_{t}\right)-r_{i t} x_{i t}
$$

Each firm makes its decision to hire capital after the shock, $\xi_{t}$, is revealed. Here $r_{i t}$ denotes the interest rate on capital in industry $i$ at date $t$ and it is determined with in the model. Asset shares are normalized so that there is one perfectly divisible equity share for each firm. Ownership of a share in firm $i$ at date $t$ entitles the consumer to the firm's profits at date $t+1$. It is also assumed (as in Lucas [29]) that the optimum levels of asset prices, capital, consumption and output form a rational expectations equilibrium.

The representative consumer solves the following problem:

$$
\begin{array}{cl}
\max & E\left[\sum_{t=0}^{\infty} \beta^{t} u\left(c_{t}\right)\right] \\
\text { subject to : } & c_{t}+x_{t}+P_{t} \cdot Z_{t} \leqslant \pi_{t} \cdot Z_{t-1}+P_{t} \cdot Z_{t-1}+\sum_{i=1}^{N} r_{i, t-1} x_{i, t-1}, \\
& c_{t}, Z_{t}, x_{i t} \geqslant 0, \\
& r_{i t}=f_{i}^{\prime}\left(x_{i t}, \xi_{t}\right), \\
& \pi_{i t}=f_{i}\left(x_{i, t-1}, \xi_{t-1}\right)-f_{i}^{\prime}\left(x_{i, t-1}, \xi_{t-1}\right) x_{i, t-1},
\end{array}
$$

where $P_{i t}$ is price of one share of firm $i$ at date $t, Z_{i t}$ is number of shares of firm $i$ owned by the consumer at date $t$, and $\pi_{i t}$ are profits of firm $i$ at date $t$. The details of the model are in Brock [2]. The first-order conditions yielding from the maximization problem are:

$$
P_{i t} u^{\prime}\left(c_{t}\right)=\beta E_{t}\left[u^{\prime}\left(c_{t+1}\right)\left(\pi_{i, t+1}+P_{i, t+1}\right)\right]
$$

and

$$
u^{\prime}\left(c_{t}\right)=\beta E_{t}\left[u^{\prime}\left(c_{t+1}\right) f_{i}^{\prime}\left(x_{i, t+1}, \xi_{t+1}\right)\right] .
$$

We use these first-order conditions to get the prices for the assets. Brock [33] shows that there is a duality between the growth model ((2.1)-(2.6))) and the asset pricing model ((2.10)-(2.14)), and the solution to the growth model is also solution to the asset pricing model. Once the solution to the growth model is obtained, the asset pricing functions can be solved for the prices for the assets by Eq. (2.15).

Now define the dividends (profits) by:

$$
\pi_{t}=\sum_{i=1}^{N} \pi_{i t}
$$

and, define the return on each asset by:

$$
R_{i t}=\frac{P_{i, t+1}+\pi_{i, t+1}}{P_{i t}} .
$$

Define the profit, consumption and output functions by:

$$
\begin{aligned}
& \pi_{i}(y, \xi)=f_{i}\left(h_{i}(y), \xi\right)-h_{i}(y) f_{i}^{\prime}\left(h_{i}(y), \xi\right), \\
& c(y)=y-\sum_{i=1}^{N} h_{i}(y), \\
& Y(y, \xi)=\sum_{i=1}^{N} f_{i}\left(h_{i}(y), \xi\right),
\end{aligned}
$$


and the asset pricing functions by:

$$
P_{i}(y) u^{\prime}(c(y))=\beta E\left[u^{\prime}(c(Y(y, \xi)))\left(P_{i}(Y(y, \xi))+\pi_{i}(y, \xi)\right)\right] .
$$

Once we have the pricing functions we next define the return function

$$
R_{i}(y)=\frac{p_{i}(Y(y, \xi))+\pi_{i}(y, \xi)}{p_{i}(y)} .
$$

From the first-order condition (2.6), the return on each asset satisfies:

$$
u_{0}\left(c_{t}\right)=E\left[u_{0}\left(c_{t+1}\right) R_{i t}\right],
$$

which is the efficiency condition from the growth model. By summing Eq. (2.6), we get that the return on the market portfolio satisfies:

$$
u_{0}\left(c_{t}\right)=E\left[u_{0}\left(c_{t+1}\right) R_{M t}\right]
$$

and so it too is efficient. This is one of the hypotheses of the CAPM, which in this model is a consequence of the optimizing behavior of the consumer.

\subsection{A numerical solution}

Except for a very special case of the utility and production functions, there is no closed-form solution for the optimal investment functions. In order to analyze the properties of the solutions to the asset pricing model we must use numerical techniques instead. Akdeniz and Dechert [30] report the technical details of the numerical solution which we will not repeat here. In this study we use that solution and explore the parameter space for solutions to the model that, to a certain extent, fit some of the stylized facts of asset markets. Our primary focus will be on the equity prices that come out of the Brock [2] asset pricing model. For the solution and the computational details please see Akdeniz and Dechert [30,31].

\subsection{Simulation}

Simulation is an invaluable tool that enhances researcher's ability to analyze dynamic economic models. It enables a researcher to investigate the empirical debates by employing those models in a laboratory environment by contemplating all possible states of an economy. As a result, more and more economists have been using simulation methods for analyzing empirical problems over the last two decades. As Judd [34] points out, the computational methods provide a strong complement to economic theory for those problems that are not analytically tractable.

In this section we present the functional forms and the parameter values that we used in the solution of the growth model. It is a common practice in the literature to calibrate the model so that the model of the economy displays certain properties in common with actual economies. In this study, we explore the parameter space for solutions to the model that, to a certain extent, fit some the stylized facts of asset markets. We use Constant Relative Risk Aversion (CRRA) utility function,

$$
u(c)=\frac{c^{\gamma}}{\gamma},
$$

where $\gamma$ is the utility curvature parameter. In keeping with the common practice in the literature we use $\gamma=-1.00$ for the value of the utility curvature parameter and we chose the value of the discount parameter, $\beta$, to be 0.97 in yearly units. On the production side, firms are characterized by the Cobb-Douglas production functions:

$$
f(x, \xi)=\theta(\xi) x^{\alpha(\xi)}+(1-\delta(\xi)) x,
$$

\begin{tabular}{|c|c|c|c|c|c|c|}
\hline State & $\alpha_{1}$ & $\alpha_{2}$ & $\theta_{1}$ & $\theta_{2}$ & $\delta_{1}$ & $\delta_{2}$ \\
\hline 1 & 0.60 & 0.50 & 0.32 & 0.24 & 0.16 & 0.12 \\
\hline 2 & 0.42 & 0.62 & 0.24 & 0.35 & 0.16 & 0.12 \\
\hline 3 & 0.54 & 0.44 & 0.16 & 0.23 & 0.16 & 0.12 \\
\hline 4 & 0.46 & 0.36 & 0.18 & 0.11 & 0.16 & 0.12 \\
\hline 5 & 0.37 & 0.48 & 0.29 & 0.19 & 0.16 & 0.12 \\
\hline 6 & 0.49 & 0.40 & 0.31 & 0.27 & 0.16 & 0.12 \\
\hline 7 & 0.40 & 0.52 & 0.22 & 0.26 & 0.16 & 0.12 \\
\hline 8 & 0.52 & 0.56 & 0.28 & 0.31 & 0.16 & 0.12 \\
\hline
\end{tabular}

where $x$ is the shock parameter in the production function. We pick the value of $\delta$ to correspond to the values that agree with aggregate data. We solve the Brock's [2] model for eight states of the economy. The parameters of the production function, $\alpha$ and $\theta$ are chosen randomly. The values for $\alpha, \theta$ and $\delta$ are reported in Table 1.

Table 1

Parameter values used in the solution of the growth model.

Notes: $\alpha, \theta$ and $\delta$ are parameters of the Cobb-Douglas production function, $f(x, \xi)=\theta(\xi) x^{\alpha(\xi)}+(1-\delta(\xi)) x$. 
We solved Brock's [2] model for three firms with the parameters reported in Table 1. We simulated the economy to obtain 100-period stock price and dividend series for 5000 times. In each simulation the computer picks a different state of the economy for each period and yields a sample path of time series of 100 stock price and dividend series. Thus each one of the 100 period time series reflects a different realization of series of states of the economy. In summary, each one of the time series consists of different possible stock price and dividend series for the market portfolio of three firms over a period of 100 years.

\section{Methodology}

\subsection{West's model and test}

Similar in the spirit to the specification test of Hausman [12], West's test compares two sets of estimates of the parameters needed to calculate the expected present discounted value of a given stock's dividend stream, with expectations conditional on current and all past dividends.

Consider the Euler equation, which expresses current price in terms of next period's price and dividend

$$
p_{t}=b \cdot E\left(p_{t+1}+d_{t+1}\right) \mid I_{t},
$$

where $b$ is the real discount factor and $p_{t}$ and $d_{t}$ are the real stock price and dividend in period $t$. $I_{t}$ is the common information set of all investors in period $t$. If the transversality condition, $\lim _{n \rightarrow \infty} b^{n} E p_{t+n} \mid I_{\mathrm{t}}=0$, holds, then there is a unique forward solution to this equation, $p_{t}=p_{t}^{*}$

$$
p_{t}^{*}=\sum_{i=1}^{\infty} b^{i} E d_{t+i} \mid I_{t}
$$

This expression gives the so-called fundamental value of the stock. If the transversality condition does not hold, then any $p_{\mathrm{t}}$ that satisfies

$$
p_{t}=p_{t}^{*}+c_{t}
$$

where

$$
c_{t}=b \cdot E c_{t+1} \mid I_{t}
$$

is also a solution. $c_{t}$ is by definition a speculative bubble.

An important feature of West's method is the use of a particular subset of $I_{t}$ to simplify estimation and testing. This information set, denoted by $H_{t}$, consists of a constant and current and lagged dividends. Rewriting Eq. (3.2) using $H_{t}$ as the conditioning information set results in the following equation:

$$
p_{t}^{*}=\sum_{i=1}^{\infty} b^{i} E d_{t+i}\left|H_{t}+\left(\sum_{i=1}^{\infty} b^{i} E d_{t+i}\left|I_{t}-\sum_{i=1}^{\infty} b^{i} E d_{t+i}\right| H_{t}\right)=\sum_{i=1}^{\infty} b^{i} E d_{t+i}\right| H_{t}+z_{t} .
$$

The term $E d_{t+i} \mid H_{t}$ is the forecast of dividends given by the past history of dividends.

West does not rely on any particular structural model for dividends. Assuming that dividends follow a stationary process, $E d_{t+i} \mid H_{t}$ is calculated as the ARIMA forecast of $d_{t+i}$. The lag length $q$ in the forecasting equation is determined empirically

$$
d_{t+1}=\mu+\phi_{1} \cdot d_{t}+\cdots+\phi_{q} \cdot d_{t-q+1}+v_{t+1} .
$$

Given the stationarity of dividends, there is a closed-form expression for $p_{t}^{*}$ in the form of a distributed lag on current and past $d_{t}$. The coefficients of the distributed lag are obtained indirectly by using Hansen and Sargent [35] formulas. These formulas express these coefficients as functions of the coefficients in the Euler and ARIMA equations. Hence this indirect method requires the estimation of the Euler equation and dividend ARIMA. If there is no bubble, then $p_{t}$ will be equal to $p_{t}^{*}$. In this case, estimating a distributed lag of $p_{t}$ on current and past $d_{t}$ will give coefficients, $m, \delta_{1}, \ldots, \delta_{t-q+2}$, which will be same as those in the distributed lag for $p_{t}^{*}$ apart from sampling error

$$
p_{t+1}=m+\delta_{1} \cdot d_{t+1}+\cdots+\delta_{q} \cdot d_{t-q+2}+w_{t+1} .
$$

West method tests the equality of the two sets of distributed lag coefficients obtained from direct and indirect estimations as explained above. The existence of a bubble is only one possible factor that can lead to a discrepancy between the two sets of coefficient estimates. Since model misspecification rather than the existence of a bubble may also give rise to such a discrepancy, diagnostic tests are applied to see if the Euler and dividend ARIMA equations are consistent with the data.

\subsection{West's estimation technique}

The estimation procedure contains the following steps: (i) identification of the order of $d_{t}$ 's ARIMA process; (ii) getting a consistent estimate of the constant ex ante discount factor, $b$, estimating the dividend process and the distributed lag of $p_{t}$ on 
$d_{t}$; (iii) calculation of the variance-covariance matrix of the parameters; (iv) calculation of basic test statistic; (v) diagnostic tests performed on the equations estimated.

The identification of the order of $d_{t}$ 's ARIMA process (i.e. lag length $q$ ) is based on the information criterion of Hannan and Quinn [36]. West's procedure requires the estimation of Eqs. (3.1), (3.4) and (3.5). Eq. (3.1) is estimated by rewriting it as:

$$
p_{t}=b \cdot\left(p_{t+1}+d_{t+1}\right)+u_{t+1}
$$

where

$$
u_{t+1}=-b \cdot\left(p_{t+1}+d_{t+1}\right)+b \cdot E\left(p_{t+1}+d_{t+1}\right) \mid I_{t} .
$$

These three equations, i.e. Eqs. 3.4, 3.5 and 3.6 are estimated by multiple-equation generalized method of moments (GMM). The Euler equation has one parameter, while the dividend ARIMA and distributed lag each has $q+1$ parameters. The set of instruments is the same across equations and includes a constant and q current and past dividends. Thus, while the Euler equation is overidentified, the other two equations are just identified.

The orthogonality conditions that the parameters in Euler, dividend and distributed lag equations should satisfy are as follows:

$$
\begin{aligned}
& \frac{1}{T-q} \sum_{t=q}^{T-1} D_{t} \cdot\left(p_{t}-x_{t} \cdot \hat{b}\right)=0 \\
& \frac{1}{T-q} \sum_{t=q}^{T-1} D_{t} \cdot\left(d_{t+1}-D_{t}^{\prime} \cdot \hat{\phi}\right)=0 \\
& \frac{1}{T-q} \sum_{t=q}^{T-1} D_{t+1} \cdot\left(p_{t+1}-D_{t+1}^{\prime} \cdot \hat{\delta}\right)=0
\end{aligned}
$$

where $D_{t}$ shows the $(q+1) \times 1$ vector of instruments, i.e. $D_{t}^{\prime}=\left\lfloor 1, d_{t}, \ldots, d_{t-q+1}\right\rfloor, x_{t}=p_{t}+1+d_{t}+1, \phi=$

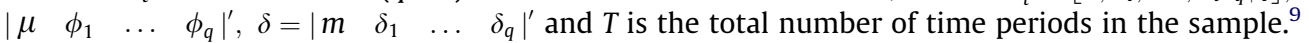

West's procedure forms a linear combination of Euler equation moments before employing multiple-equation GMM estimation. This linear combination becomes the single moment that determines the coefficient estimate, $\hat{b}$. The coefficients of this linear combination are obtained as follows. Let $D$ be the $(T-q) \times(q+1)$ matrix of stacked instruments and $X$ be a $(T-q) \times 1$ vector of explanatory variables, where

$$
D^{\prime}=\left|\begin{array}{lllll}
D_{q} & \cdots & \cdots & D_{T-1}
\end{array}\right| \text { and } X^{\prime}=\left|\begin{array}{|llll}
p_{q+1}+d_{q+1} & \cdots & \cdots & p_{T}+d_{T}
\end{array}\right| .
$$

First, an initial estimate of $\mathrm{b}$ is obtained by two-stage least squares (2SLS). The 2SLS residuals are used to construct an estimator of the asymptotic covariance matrix of the Euler equation sample moments. The form for this covariance matrix, denoted by Sd, allows heteroskedasticity but no serial correlation. The linear combination of Euler equation moments that determines $\hat{b}$ is obtained by using the elements of the $1 \times(q+1)$ vector $X \cdot D^{\prime} \cdot\left[(T-q) \cdot \hat{S}_{d}\right]^{-1}$ as coefficients.

Multiple-equation GMM stacks the sample moments of three equations into a $(2 q+3) \times 1$ vector

$$
h_{T}(\hat{\theta})=\frac{1}{T-q} \sum_{t=q}^{T-1} h_{t}(\hat{\theta})=\frac{1}{T-q}\left|\begin{array}{c}
\sum_{t=q}^{T-1} X \cdot D^{\prime} \cdot\left[(T-q) \cdot \hat{S}_{d}\right]^{-1} \cdot D_{t} \cdot\left(p_{t}-x_{t} \cdot \hat{b}\right) \\
\sum_{t=q}^{T-1} D_{t} \cdot\left(d_{t+1}-D_{t}^{\prime} \cdot \hat{\phi}\right) \\
\sum_{t=q}^{T-1} D_{t+1} \cdot\left(p_{t+1}-D_{t+1}^{\prime} \cdot \hat{\delta}\right)
\end{array}\right| .
$$

The weighting matrix in the multiple-equation GMM estimation is:

$$
\widehat{W}=\left|\begin{array}{ccc}
{\left[(T-q) \cdot \widehat{S}_{d}\right]_{q+1 \times q+1}^{-1}} & 0 & 0 \\
0 & I_{q+1 \times q+1} & 0 \\
0 & 0 & I_{q+1 \times q+1}
\end{array}\right|,
$$

where $I_{q+1 \times q+1}$ denotes a $(q+1) \times(q+1)$ identity matrix. Given that each equation in the system is exactly identified, GMM estimator becomes the multiple-equation instrumental variables (IV) estimator. Due to the block diagonality of $\frac{\partial h_{T}^{\prime}}{\partial \theta}$, the estimator is just a collection of single-equation IV estimators. Since in the estimation of the dividend process and distributed lag explanatory variables serve as instruments, the coefficient estimates from multiple-equation GMM are identical to those from equation-by-equation OLS estimation. Moreover, discount factor estimate from multiple-equation GMM is equal to that from single equation GMM using a prespecified weighting matrix $\widehat{W}=\hat{S}_{d}^{-1}$.

\footnotetext{
${ }^{9}$ The sample contains $T$ observations. Since lagged dividends are used as explanatory variables $T-q$ observations are used in estimations.
} 
After the estimation of parameters, their variance-covariance matrix is calculated. This requires an estimate of the asymptotic variance-covariance matrix of moments, denoted by $S$. The Bartlett kernel-based estimator of $S$, which allows heteroskedasticity and autocorrelation, is used:

$$
\begin{aligned}
& \widehat{S}=\widehat{\Omega}_{0}+\sum_{i=1}^{m} K(i, m) \cdot\left(\widehat{\Omega}_{i}+\widehat{\Omega}_{i}^{\prime}\right), \\
& \widehat{\Omega}_{i}=\frac{1}{T-q} \sum_{i=-\infty}^{\infty} \hat{h}_{t} \cdot \hat{h}_{t-i}^{\prime},
\end{aligned}
$$

where $\Omega_{i}$ is the $i$ th order autocovariance matrix, $K$ is the Bartlett kernel and $m$ is the Newey-West fixed bandwidth. Given the above $\hat{S}$ and $\hat{W}$ as defined before, the variance-covariance matrix of the parameters is:

$$
V(\theta)=\left(\frac{\partial h_{T}^{\prime}}{\partial \theta} \cdot W \cdot \frac{\partial h_{T}}{\partial \theta^{\prime}}\right)^{-1} \cdot \frac{\partial h_{T}^{\prime}}{\partial \theta} \cdot W \cdot S \cdot W \cdot \frac{\partial h_{T}}{\partial \theta^{\prime}} \cdot\left(\frac{\partial h_{T}^{\prime}}{\partial \theta} \cdot W \cdot \frac{\partial h_{T}}{\partial \theta^{\prime}}\right)^{-1},
$$

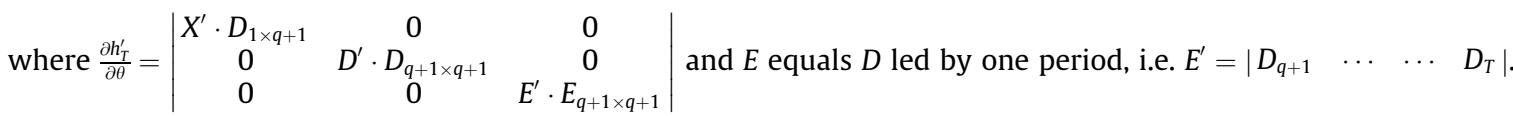

The basic test statistic is calculated as follows. Under the null hypothesis of no bubbles, the regression coefficients in all equations are estimated consistently. When the direct and indirect estimates of the expected present discounted value parameters are compared, then they should be the same, apart from sampling error. Hence, the test is based on the following cross-equation restrictions on the coefficients in Eqs. (3.4)-(3.6), which are obtained by applying Hansen and Sargent [35] formulas:

$$
\begin{aligned}
& 0=m-b \cdot(1-b)^{-1} \Phi(b)^{-1} \mu, \\
& 0=\delta_{1}-\left[\Phi(b)^{-1}-1\right], \\
& 0=\delta_{j}-\Phi(b)^{-1} \sum_{k=j}^{q} b^{k-j+1} \Phi_{k}, \quad j=2, \ldots, q,
\end{aligned}
$$

where

$$
\Phi(b)^{-1}=\left[1-\sum_{i=1}^{q} b^{i} \phi_{i}\right]^{-1}
$$

Let $R(\theta)$ denote these $q+1$ constraints. The null hypothesis is that $R(\theta)=0$. The test statistic is calculated as:

$$
R(\hat{\theta})^{\prime} \cdot\left[\left(\frac{\partial R}{\partial \hat{\theta}}\right) \cdot V \cdot\left(\frac{\partial R}{\partial \hat{\theta}}\right)^{\prime}\right]^{-1} \cdot R(\hat{\theta})
$$

The derivative of $R(\theta)$ is calculated analytically. Under the null hypothesis, the statistic is asymptotically distributed as a chisquared random variable with $q+1$ degrees of freedom.

As was discussed before, since model misspecification rather than the existence of a bubble may also give rise to a significant value of the test statistic, diagnostic tests on Euler and dividend ARIMA equations are performed to confirm that other sources of misspecification are not present. The first diagnostic check examines serial correlation in the residuals of those two equations. Under rational expectations, the expectational error $u_{t+1}$ should display no autocorrelation. Similarly, the innovation in the dividend ARIMA, $v_{t+1}$, should also be serially uncorrelated, if the dividend process is not misspecified. Ljung-Box statistic is calculated for these two residuals. A second diagnostic test, Hansen's [37] test of instrument-residual orthogonality, is performed on the Euler equation

$$
J \text { statistics }=\left[\sum_{t=q}^{T} D_{t} \cdot\left(p_{t}-x_{t} \cdot \hat{b}\right)\right]^{l} \cdot\left(T \cdot \hat{S}_{d}\right)^{-1} \cdot\left[\sum_{t=q}^{T} D_{t} \cdot\left(p_{t}-x_{t} \cdot \hat{b}\right)\right] .
$$

Under the null hypothesis that the Euler equation is not misspecified, the test statistic is asymptotically distributed as a chisquared random variable with $q$ degrees of freedom. This test checks for the misspecification of the Euler equation due to expectational irrationality and time variation in discount rates that is correlated with dividends.

\subsection{Use of West's Bubble test with simulated data}

As was described in Section 2.4, our initial data consists of 5000 independent samples, each containing a price and a dividend series for 100 periods. For each sample, the stationarity of dividends is tested by using the Augmented Dickey Fuller test. Dividend series are non-stationary for 168 samples. A modified version of West test can be applied to samples with 
Table 2

Summary of estimation results - Euler equation.

\begin{tabular}{|c|c|c|c|c|}
\hline$q$ & & $b$ & $\rho_{\text {Euler }}$ & $H$ \\
\hline \multirow[t]{8}{*}{2} & Mean & 0.969 & -0.020 & 2.646 \\
\hline & Std. dev. & 0.003 & 0.081 & 1.547 \\
\hline & Median & 0.969 & -0.020 & 2.456 \\
\hline & Minimum & 0.960 & -0.200 & 0.008 \\
\hline & Maximum & 0.977 & 0.198 & 5.989 \\
\hline & 2.5th Percentile & 0.964 & -0.164 & 0.229 \\
\hline & 97.5th Percentile & 0.975 & 0.144 & 5.611 \\
\hline & \# Sign & 913 & & \\
\hline \multirow[t]{8}{*}{3} & Mean & 0.969 & -0.031 & 4.210 \\
\hline & Std. dev. & 0.003 & 0.087 & 1.813 \\
\hline & Median & 0.969 & -0.041 & 4.204 \\
\hline & Minimum & 0.960 & -0.198 & 0.141 \\
\hline & Maximum & 0.980 & 0.194 & 7.797 \\
\hline & 2.5th Percentile & 0.963 & -0.174 & 0.987 \\
\hline & 97.5th Percentile & 0.975 & 0.147 & 7.375 \\
\hline & \# Sign & 482 & & \\
\hline \multirow[t]{8}{*}{4} & Mean & 0.968 & -0.040 & 5.520 \\
\hline & Std. dev. & 0.003 & 0.090 & 2.169 \\
\hline & Median & 0.968 & -0.042 & 5.528 \\
\hline & Minimum & 0.960 & -0.200 & 0.758 \\
\hline & Maximum & 0.979 & 0.192 & 9.484 \\
\hline & 2.5th Percentile & 0.962 & -0.190 & 1.732 \\
\hline & 97.5th Percentile & 0.974 & 0.153 & 9.321 \\
\hline & \# Sign & 200 & & \\
\hline
\end{tabular}

Notes: The model is given by Eq. (3.6) in the text. This table summarizes the results of 1595 independent samples, each containing a price and a dividend series for 100 periods. These samples are grouped based on the empirically determined lag length, denoted by $q$, in the dividend ARIMA equation. Results are shown separately for lag length groups between two and four for convenience of reporting. These groups contain 913,482 and 200 samples, respectively. $b$ is the real discount factor. $\rho$ is first-order serial correlation of disturbance. $H$ denotes Hansen's [36] test of instrument-residual orthogonality, it is distributed $\chi^{2}(q)$. \# Sign denotes the total number of samples in which a coefficient is significant at $5 \%$ level.

non-stationary dividend series, however since these cases represent a small portion of our data, the analysis will be based on samples characterized by stationary dividends.

To minimize the effect of model misspecification on our results, we filter the generated data based on the following two criteria. First, we eliminate the samples for which the value of lag length $q$ in the ARIMA forecasting equation is less than two. This filter reflects the requirement that the information set, $H_{t}$, consisting of current and lagged dividends contains useable information. Second, we eliminate those samples that could not pass the two diagnostic checks discussed before. Thus, we kept only those samples for which we are more confident that the rejection of the null hypothesis of "no bubble" does not result from certain factors other than bubbles.

The use of these two filters eliminated 2576 and 486 samples, respectively. The impact of the second filter is to a large extent due to the rejection of instrument-residual orthogonality condition (433 cases). Serial correlation in the residuals of the Euler and/or dividend ARIMA equations was detected in only 53 samples. This leaves 1770 samples to be used in the analysis. These samples are grouped based on the value of lag length $q$ in the ARIMA forecasting equation. Examining relative frequencies indicates that most of the samples, i.e. 1595 out of 1770 , fall in one the following three groups: $q=2, q=3$ and $q=4{ }^{10}$ Therefore, in the remainder of the paper, only results for these three groups will be presented due to space limitation.

The results of estimating Eqs. (3.4)-(3.6) are shown in Tables 2-4. These tables contain descriptive statistics (mean, standard deviation, median, minimum, maximum, 2.5th percentile and 97.5th percentile) both for relevant diagnostic test statistics and coefficient estimates across simulations. These diagnostic tests confirm that samples used in the analysis do not show misspecification. Besides descriptive statistics across samples, these tables indicate for each coefficient the number of estimations in which it is found statistically significant at $5 \%$ level.

Table 2 presents the estimation results of Euler equation (3.6). Columns 4 and 5 give information on the two statistics used for diagnosis testing. Column 4 gives the distribution of the first-order serial correlation coefficient of the disturbance. Across the three lag length groups, median values vary from -0.021 to -0.044 . Given the sample size of 100 , the usual $95 \%$ confidence band is $\pm 2 / 10= \pm 0.2$. Column 5 reports the distribution of Hansen's [37] instrument-residual orthogonality test statistics. Across the three groups median values range from 2.46 to 5.50 . The $5 \%$ critical values of this statistic for the three lag lengths are 5.99, 7.81 and 9.49, respectively. The figures in columns 4 and 5 indicate that the specification for Euler equation appears acceptable, since for all the samples used in the analysis the two diagnostic test statistics are below their $5 \%$ critical values. The discount factor $b$ in three specifications has a mean value of 0.97 and it varies between 0.96 and 0.98 . This agrees with the parameter value used in simulating the data. For the three lag length groups, all the coefficient estimates for $b$ are found significant at 5\% level (913, 482 and 200, respectively).

\footnotetext{
$\overline{10}$ Lag length groups for q between 5 and 12 contain 95, 39, 18, 8, 5, 5, 3 and 2, samples, respectively.
} 
Table 3

Summary of estimation results - dividend ARIMA.

\begin{tabular}{|c|c|c|c|c|c|c|c|c|}
\hline$q$ & & $\mu$ & $\Phi_{1}$ & $\Phi_{2}$ & $\Phi_{3}$ & $\Phi_{4}$ & $\rho_{\text {ARIMA }}$ & $Q(30)$ \\
\hline \multirow[t]{8}{*}{2} & Mean & 0.111 & 0.176 & 0.226 & & & -0.015 & 22.059 \\
\hline & Std. dev. & 0.023 & 0.087 & 0.078 & & & 0.022 & 5.965 \\
\hline & Median & 0.110 & 0.177 & 0.226 & & & -0.016 & 21.596 \\
\hline & Minimum & 0.044 & -0.039 & -0.090 & & & -0.084 & 8.050 \\
\hline & Maximum & 0.203 & 0.565 & 0.478 & & & 0.057 & 43.503 \\
\hline & 2.5th Percentile & 0.067 & 0.013 & 0.046 & & & -0.056 & 11.879 \\
\hline & 97.5th Percentile & 0.160 & 0.346 & 0.383 & & & 0.031 & 35.931 \\
\hline & \# Sign & 913 & 476 & 680 & & & & \\
\hline \multirow[t]{8}{*}{3} & Mean & 0.090 & 0.159 & 0.140 & 0.215 & & -0.009 & 20.600 \\
\hline & Std. dev. & 0.021 & 0.090 & 0.093 & 0.071 & & 0.021 & 5.807 \\
\hline & Median & 0.088 & 0.160 & 0.146 & 0.223 & & -0.010 & 19.883 \\
\hline & Minimum & 0.043 & -0.127 & -0.159 & -0.113 & & -0.055 & 7.429 \\
\hline & Maximum & 0.189 & 0.476 & 0.404 & 0.363 & & 0.054 & 43.436 \\
\hline & 2.5th Percentile & 0.058 & -0.008 & -0.063 & 0.022 & & -0.046 & 11.956 \\
\hline & 97.5th Percentile & 0.141 & 0.336 & 0.324 & 0.326 & & 0.037 & 35.342 \\
\hline & \# Sign & 482 & 223 & 168 & 356 & & & \\
\hline \multirow[t]{8}{*}{4} & Mean & 0.081 & 0.152 & 0.107 & 0.123 & 0.181 & -0.007 & 19.649 \\
\hline & Std. dev. & 0.023 & 0.103 & 0.088 & 0.104 & 0.101 & 0.023 & 5.186 \\
\hline & Median & 0.077 & 0.153 & 0.113 & 0.136 & 0.205 & -0.010 & 19.478 \\
\hline & Minimum & 0.038 & -0.142 & -0.103 & -0.165 & -0.144 & -0.066 & 10.145 \\
\hline & Maximum & 0.167 & 0.426 & 0.339 & 0.339 & 0.334 & 0.054 & 38.564 \\
\hline & 2.5th Percentile & 0.048 & -0.083 & -0.068 & -0.116 & -0.097 & -0.047 & 11.247 \\
\hline & 97.5th Percentile & 0.136 & 0.363 & 0.278 & 0.308 & 0.308 & 0.041 & 31.176 \\
\hline & \# Sign & 198 & 79 & 61 & 73 & 120 & & \\
\hline
\end{tabular}

Notes: The model is given by Eq. (3.4) in the text. This table summarizes the results of 1595 independent samples, each containing a price and a dividend series for 100 periods. These samples are grouped based on the empirically determined lag length, denoted by $q$, in the dividend ARIMA equation. Results are shown separately for lag length groups between two and four for convenience of reporting. These groups contain 913 , 482 and 200 samples, respectively. $\rho$ is first-order serial correlation of disturbance. $Q(30)$ is Ljung-Box $Q$ statistic. It is distributed $\chi^{2}(30)$. For $5 \%$ significance level, critical values for $\chi^{2}(24)$ and $\chi^{2}(30)$ are 36.42 and 43.77, respectively. \# Sign denotes the total number of samples in which a coefficient is significant at $5 \%$ level.

Table 4

Summary of estimation results - distributed lag.

\begin{tabular}{|c|c|c|c|c|c|c|}
\hline$q$ & & $\mathrm{~m}$ & $\delta_{1}$ & $\delta_{2}$ & $\delta_{3}$ & $\delta_{4}$ \\
\hline \multirow[t]{8}{*}{2} & Mean & 1.681 & 12.415 & 11.029 & & \\
\hline & Std. dev. & 0.712 & 1.831 & 1.934 & & \\
\hline & Median & 1.699 & 12.340 & 10.895 & & \\
\hline & Minimum & -0.715 & 6.527 & 4.922 & & \\
\hline & Maximum & 4.181 & 18.837 & 18.041 & & \\
\hline & 2.5th Percentile & 0.356 & 9.059 & 7.646 & & \\
\hline & 97.5th Percentile & 3.048 & 15.963 & 15.003 & & \\
\hline & \# sign & 719 & 913 & 913 & & \\
\hline \multirow[t]{8}{*}{3} & Mean & 0.449 & 11.525 & 9.864 & 8.689 & \\
\hline & Std. dev. & 0.676 & 1.373 & 1.349 & 1.363 & \\
\hline & Median & 0.406 & 11.559 & 9.859 & 8.659 & \\
\hline & Minimum & -1.250 & 6.493 & 5.462 & 4.851 & \\
\hline & Maximum & 2.554 & 14.833 & 14.375 & 12.715 & \\
\hline & 2.5th Percentile & -0.675 & 8.973 & 7.180 & 5.961 & \\
\hline & 97.5th Percentile & 1.978 & 14.052 & 12.547 & 11.208 & \\
\hline & \# sign & 113 & 482 & 482 & 482 & \\
\hline \multirow[t]{8}{*}{4} & Mean & -0.181 & 10.548 & 8.890 & 7.460 & 6.598 \\
\hline & Std. dev. & 0.681 & 1.133 & 1.127 & 1.089 & 1.169 \\
\hline & Median & -0.198 & 10.615 & 8.925 & 7.489 & 6.706 \\
\hline & Minimum & -1.969 & 7.338 & 6.208 & 4.592 & 3.832 \\
\hline & Maximum & 1.748 & 13.627 & 12.792 & 11.595 & 10.122 \\
\hline & 2.5th Percentile & -1.469 & 8.125 & 6.580 & 5.550 & 4.343 \\
\hline & 97.5th Percentile & 1.161 & 12.842 & 11.246 & 9.716 & 8.695 \\
\hline & \# sign & 42 & 200 & 200 & 200 & 200 \\
\hline
\end{tabular}

Notes: The model is given by Eq. (3.5) in the text. This table summarizes the results of 1595 independent samples, each containing a price and a dividend series for 100 periods. These samples are grouped based on the empirically determined lag length, denoted by $q$, in the dividend ARIMA equation. Results are shown separately for lag length groups between two and four for convenience of reporting. These groups contain 913 , 482 and 200 samples, respectively. \# Sign denotes the total number of samples in which a coefficient is significant at $5 \%$ level. 
Table 5

Summary of estimation results - West's test statistic.

\begin{tabular}{|c|c|c|}
\hline$q$ & & W \\
\hline 2 & $\begin{array}{l}\text { Mean } \\
\text { Std. dev. } \\
\text { Median } \\
\text { Minimum } \\
\text { Maximum } \\
\text { 2.5th Percentile } \\
\text { 97.5th Percentile }\end{array}$ & $\begin{array}{r}118.934 \\
72.471 \\
100.793 \\
23.588 \\
620.215 \\
38.215 \\
285.658\end{array}$ \\
\hline 3 & $\begin{array}{l}\text { Mean } \\
\text { Std. Dev. } \\
\text { Median } \\
\text { Minimum } \\
\text { Maximum } \\
\text { 2.5th Percentile } \\
\text { 97.5th Percentile }\end{array}$ & $\begin{array}{r}217.464 \\
138.962 \\
189.163 \\
35.560 \\
912.189 \\
58.867 \\
588.653\end{array}$ \\
\hline 4 & $\begin{array}{l}\text { Mean } \\
\text { Std. Dev. } \\
\text { Median } \\
\text { Minimum } \\
\text { Maximum } \\
\text { 2.5th Percentile } \\
\text { 97.5th Percentile }\end{array}$ & $\begin{array}{r}254.676 \\
167.444 \\
211.733 \\
46.103 \\
1,123.963 \\
73.832 \\
723.034\end{array}$ \\
\hline
\end{tabular}

Notes: This table summarizes the results of 1595 independent samples, each containing a price and dividend series for 100 periods. These samples are grouped based on the empirically determined lag length, denoted by $q$, in the dividend ARIMA equation. Results are shown separately for lag length groups between two and four for convenience of reporting. These groups contain 913, 482 and 200 samples, respectively. Under the null hypothesis, West's test statistics, denoted by $W$, is asymptotically distributed as a chisquared random variable with $q+1$ degrees of freedom. For $5 \%$ significance level, critical values for $\chi^{2}(3)$, $\chi^{2}(4)$ and $\chi^{2}(5)$ are $7.81,9.49$ and 11.07 , respectively.

Table 3 reports the results for dividend ARIMA equation (3.4). Column 8 shows descriptive statistics for the first-order serial correlation coefficient of the disturbance. Across the three lag length groups, median values vary from -0.010 to -0.016 . Column 9 gives the distribution of the second serial correlation test, namely Ljung-Box $Q(30)$ statistic for the residuals. Across the three lag length groups, median values vary from 19.478 to 21.596 . It is distributed $\chi^{2}$ (30). For $5 \%$ significance level the critical value is 43.77 . Overall, the figures in these two columns confirm that for all the samples used in the analysis there is no evidence of serial correlation in the residuals of Eq. (3.4). Columns 3-7 report the descriptive statistics for coefficient estimates. Both the mean and median values of the intercept as well as the coefficients of lagged dividends are positive in all the three lag length groups. The intercept is found significant at $5 \%$ level in all estimations, while for the other coefficients this occurs less frequently.

Estimates of the final equation, the distributed lag of price on current and past dividends (3.5), are reported in Table 4. It is notable that, for the three lag length groups, the coefficients of dividends are found significant at $5 \%$ level in all estimations. For the three lag length groups, the median values of all coefficient estimates, except that of the intercept for the third group, are positive.

The test of the null hypothesis that bubbles are absent is given in Table 5. The table reports the distribution of West's test statistic. Under the null this statistic is distributed as a chi-squared random variable with $q+1$ degrees of freedom. For $5 \%$ significance level, critical values for $\chi^{2}(3), \chi^{2}(4)$ and $\chi^{2}(5)$ are $7.81,9.49$ and 11.07 , respectively. For the three lag length groups even the minimum value of the test statistic exceeds the relevant critical value. In other words, for all the 1595 samples used in the analysis the hypothesis that the absence of bubble is rejected.

\section{Conclusion}

In this study, we follow the argument of Dezhbakhsh and Demirguc-Kunt [13] and design an experiment to examine the ability of the West's test to detect bubbles. We simulated Brock's [2] general equilibrium model of asset pricing to obtain equity price and dividend series to be used in place of actual data in West tests. Specifically, we solved Brock's model for three firms by using parameter space that, to a certain extent, fit some of the stylized facts of asset markets. In each simulation the process picks one of the eight different states of the economy for each period and yields stock price and dividend series for the market portfolio of three firms over a period of 100 years.

We applied West's test to 1595 samples for which we are confident that the rejection of the null hypothesis of "no bubble" does not result from certain factors other than bubbles. Although it is impossible to have bubbles in the simulated data by the design of the model, the West test flags for bubbles. It is notable that even the minimum value of the West's test statistic across simulations exceeds the relevant critical value. In other words, for all the 1595 samples the hypothesis that the absence of bubble is rejected. 
Our evidence is based on a particular parameter space, which was chosen to fit some of the stylized facts of asset markets. One can argue that the choice of some other parameter set might give different results. However, providing evidence, even based on a particular parameter space, is sufficient to confirm that the rejection of the no-bubble hypothesis of West's test is not necessarily an indication of the existence of a bubble.

In interpreting our evidence, one should also consider other criticisms on West's test. Flood et al. [17] raised two such points. Their first criticism is that in West the Euler equation is derived and tested for two consecutive periods, ignoring the issue that theoretically the relation should hold between any two periods in the future. They argue that, as a result, the estimate of discount factor may be biased. Their second criticism is that West's test may suffer from the so-called peso problem. In other words, investors in the market might attribute a small probability to an event that will have a large impact on the asset price. It may be the case that this event does not occur in the sample, while its effect is reflected in prices. For the researcher, who does not know this perception of investors in the market it is the omitted variables problem. Although these criticisms may be relevant if one uses real data, they are irrelevant for our experimental design. First, our data is generated based on Brock's model [2], which similar to West employs the Euler equation for two consecutive periods. Second, since we use a large number of simulated data rather than a single sample, the peso problem cannot be an issue.

In conclusion, we believe that our evidence gives support to the criticism of Dezhbakhsh and Demirguc-Kunt [13] that the approximation used in calculating the test statistic in West, could exaggerate the chi-square statistic resulting in a rejection of the "no-bubble" hypothesis when there are no bubbles.

\section{References}

[1] K. West, A specification test for speculative bubbles, Quart. J. Econ. 102 (3) (1987) 553-580.

[2] W.A. Brock, Asset prices in a production economy, in: J.J. McCall (Ed.), The Economics of Information and Uncertainty, The University of Chicago Press, Chicago, 1982, pp. 1-46.

[3] R. Shiller, Do stock prices move too much to be justified by subsequent changes in dividends?, Am Econ. Rev. 71 (3) (1981) $421-436$.

[4] J. Tirole, Asset bubbles and overlapping generations, Econometrica 53 (6) (1985) 1499-1528.

[5] O. Blanchard, M. Watson, Bubbles, rational expectations, and financial markets, in: P. Wachter (Ed.), Crises in the Economic and Financial Structure, Lexington Books, Lexington, 1982, pp. 295-315.

[6] L. Akdeniz, A. Altay-Salih, T. Ok, Are stock prices too volatile to be justified by the dividend discount model?, Physica A 376 (2007) $433-444$

[7] R.P. Flood, P. Garber, Market fundamentals versus price level bubbles: the first tests, J. Polit. Econ. 88 (4) (1980) 745-770.

[8] R.P. Flood, P. Garber, Speculative Bubbles, Speculative Attacks and Policy Switching, MIT Press, Cambridge, 1994.

[9] K. Froot, M. Obstfeld, Intrinsic bubbles: the case of stock prices, Am. Econ. Rev. 81 (5) (1991) 1189-1214.

[10] J. Driffill, M. Sola, Intrinsic bubbles and regime switching, J. Monetary Econ. 42 (2) (1998) 357-373.

[11] R. Shiller, Stock prices and social dynamics, Brookings Pap. Econ. Act. 1984 (2) (1984) 457-498

[12] J.A. Hausman, Specification tests in econometrics, Econometrica 46 (6) (1978) 1251-1271.

[13] H. Dezbakhsh, A. Demirguc-Kunt, On the presence of speculative bubbles in stock prices, J. Finan. Quant. Anal. 25 (1) (1990) $101-112$.

[14] R.S. Gurkaynak, Econometric tests of asset price bubbles: taking stock, J. Econ. Surv. 22 (1) (2008) 166-186.

[15] A. Casella, Testing for rational bubbles with exogenous or endogenous fundamentals: the German hyperinflation once more, J. Monetary Econ. 24 (1) (1989) $109-122$.

[16] R.A. Meese, Testing for bubbles in exchange markets: a case of sparkling rates, J. Polit. Econ. 94 (2) (1986) 345-373.

[17] R.P. Flood, R.J. Hodrick, P. Kaplan, An evaluation of recent evidence on stock price bubbles, in: R.P. Flood, P.M. Garber (Eds.), Speculative Bubbles, Speculative Attacks and Policy Switching, MIT Press, Cambridge, 1994, pp. 105-133.

[18] R.H. Thaler, Advances in Behavioral Finance, vol. II, Princeton University Press, New Jersey, 2005.

[19] H. Shefrin, Beyond Greed and Fear: Understanding Behavioral Finance and Psychology of Investing, Harvard Business School Press, Boston, 2000.

[20] H. Shefrin, Behavioral Finance (The International Library of Critical Writings in Financial Economics), vols. I-IV, Edward Elgar Publishing, Cheltenham, 2001

[21] N. Barberis, R.H. Thaler, A survey of behavioral finance, in: G. Constantinides, R. Stulz, M. Harris (Eds.), Handbook of the Economics of Finance, North Holland, Amsterdam, 2003, pp. 1054-1123.

[22] A. Vissing-Jorgensen, Perspectives on behavioral finance: does irrationality disappear with wealth? Evidence from expectations and actions, in: M. Gertler, K. Rogoff (Eds.), NBER Macroeconomics Annual 2003, NBER, Cambridge, 2004, pp. 139-208.

[23] D. Abreu, M.K. Brunnermeier, Bubbles and crashes, Econometrica 71 (1) (2003) 173-204.

[24] S.L. Heston, M. Loewenstein, G.A. Willard, Options and bubbles, Rev. Finan. Stud. 20 (2) (2007) 359-390.

[25] L. Pastor, P. Veronesi, Was there a NASDAQ bubble in the late 1990s?, J Finan. Econ. 81 (1) (2006) 61-100.

[26] L.L. Ghezzi, C. Piccardi, Stock valuation along a Markov chain, Appl. Math. Comput. 141 (2-3) (2003) 385-393.

[27] M. Nwogugu, Further critique of GARCH/ARMA/VAR/EVT stochastic-volatility models and related approaches, Appl. Math. Comput. 182 (2) (2006) $1735-1748$.

[28] J. Cunado, L.A. Gil-Alana, F. Perez de Garcia, A test for rational bubbles in the NASDAQ stock index: a fractionally integrated approach, J. Bank. Finan. 29 (10) (2005) 2633-2654.

[29] R.E. Lucas, Asset prices in an exchange economy, Econometrica 46 (6) (1978) 1429-1445.

[30] L. Akdeniz, W.D. Dechert, Do CAPM results hold in a dynamic economy? A numerical analysis, J. Econ. Dynam. Control 21 (6) (1997) 981-1004.

[31] L. Akdeniz, W.D. Dechert, The equity premium in Brock's asset pricing model, J. Econ. Dynam. Control 31 (7) (2007) $2263-2292$.

[32] L. Akdeniz, Risk and return in a dynamic general equilibrium model, J. Econ. Dynam. Control 24 (6) (2000) 1079-1096.

[33] W.A. Brock, An integration of stochastic growth theory and the theory of finance. Part I: The growth model, in: J. Green, J. Scheinkman (Eds.), General Equilibriumm Growth and Trade, Academic Press, New York, 1979, pp. 165-192.

[34] K.L. Judd, Computational economics and economic theory: substitutes or complements?, J Econ. Dynam. Control 21 (6) (1997) 907-942.

[35] L.P. Hansen, T.J. Sargent, Formulating and estimating dynamic linear rational expectations models, in: R.E. Lucas, T.J. Sargent (Eds.), Rational Expectations and Econometric Practice, University of Minnesota Press, Minneapolis, 1981, pp. 91-126.

[36] E.J. Hannan, B.G. Quinn, The determination of the order of an autoregression, J. Roy. Stat. Soc. B 41 (2) (1979) $190-195$.

[37] L.P. Hansen, Large sample properties of generalized method of moments estimators, Econometrica 50 (4) (1982) 1029-10514. 